\title{
Avaliação da Distribuição de Focos de Calor às Margens de Rodovias Federais no Estado do Ceará/Brasil
}

\author{
Davi Teixeira Gomes ${ }^{1,3}$ (D), Meiry Sayuri Sakamoto ${ }^{2}$, Antônio Elder Ferreira da Silva ${ }^{1}$ \\ ${ }^{1}$ Centro de Ciências e Tecnologia, Universidade Estadual do Ceará, Fortaleza, CE, Brasil. \\ ${ }^{2}$ Fundação Cearense de Meteorologia e Recursos Hidricos, Fortaleza, CE, Brasil. \\ ${ }^{3}$ Mestrado Profissional em Climatologia e Aplicações nos Países da CPLP e África, \\ Universidade Estadual do Ceará, Fortaleza, CE, Brasil.
}

Recebido em: 2 de Abril de 2020 - Aceito em: 19 de Junho de 2020

\begin{abstract}
Resumo
O objetivo deste trabalho é avaliar a distribuição dos focos de calor no entorno de rodovias federais no estado do Ceará/ Brasil. A análise foi realizada a partir de dados de focos de calor gerados por satélite e de dados meteorológicos coletados entre 2002 a 2018. Os resultados mostram que os focos de calor no estado concentram-se no segundo semestre do ano, com $87 \%$ dos focos sendo registrados entre os meses de setembro e dezembro. A relação entre a precipitação anual e a incidência de focos de calor não é direta, ou seja, anos mais secos, não apresentam, necessariamente, maior quantidade de focos de calor. No período analisado, em anos com maiores índices pluviométricos, observou-se maior número de focos de calor. Estima-se que a causa esteja relacionada com maior disponibilidade de vegetação para queima, bem como a realização de queimadas para o preparo das terras para plantio. Em média, 7\% do total dos focos de calor no estado encontram-se no entorno das rodovias. Nos anos analisados, esse percentual variou entre 5\% a $12 \%$. Nas três rodovias estudadas (BR 020, BR 116 e BR 222) foram identificadas as áreas com maior risco a incêndios florestais. Os dados meteorológicos e a análise dos resultados do índice de risco de incêndio de Angstron confirmam que o segundo semestre é o período que apresenta condições atmosféricas favoráveis a ignição e propagação rápida de incêndios em vegetação, principalmente no interior do estado. O litoral, por influência da maritimidade e de regime de chuvas mais prolongado, não apresentou alto índice de risco de incêndio. Os resultados poderão subsidiar o planejamento de prevenção e mitigação de desastres envolvendo a dinâmica dos transportes e dos incêndios florestais.
\end{abstract}

Palavras-chave: focos de calor, risco a incêndio florestal, índice de Angstron.

\section{Evaluation of the Distribution of Heat Spots on the Margins of Federal Highways in the State of Ceará/Brazil}

\begin{abstract}
The objective of this paper is to evaluate the distribution of heat sources around federal highways in the state of Ceará/ Brazil. The analysis was carried out from satellite generated heat sources and meteorological data collected between 2002 and 2018. The results show that hotspots in the state are concentrated in the second half of the year, with $87 \%$ of the hotspots being recorded between the months of September and December. The relationship between annual precipitation and the incidence of hotspots is not direct, drier years do not necessarily show more hotspots. In the analyzed period, in years with higher rainfall rates, a greater number of hot spots were observed. It is estimated that the cause is related to greater availability of vegetation for burning, as well as the realization of fires for the preparation of land for planting. On average, $7 \%$ of the total number of hotspots in the state are around the roads. In the years analyzed, this percentage varied between 5\% and 12\%. In the three roads studied (BR 020, BR 116 and BR 222) the areas with the highest risk of forest fires were identified. The meteorological data and the analysis of the results of the Angstron fire risk index confirm that the second semester is the period that presents favorable atmospheric conditions for the ignition and rapid spread of fires in vegetation, mainly inside the state. The coastline, due to the influence of the sea and longer rainfall regime, did not present a high fire risk index. The results may subsidize disaster prevention and mitigation planning involving the dynamics of transportation and forest fires.
\end{abstract}

Keywords: hot spots, forest fire risk, Angstron index.

Autor de correspondência: Davi Teixeira Gomes, ten.davi.teixeira@gmail.com. 


\section{Introdução}

No Brasil, assim como na América do Sul, a quase totalidade dos incêndios florestais tem como causa principal a ação do homem, por motivos variados, tais como: limpeza e renovação de pastagens, queima de restos culturais para preparação de plantios, eliminação de material lenhoso resultante de desmatamentos, vandalismo, disputas fundiárias, protestos sociais etc. A ação do fogo sobre a floresta atinge não só a cobertura vegetal, mas, também impacta o solo, a fauna e a atmosfera, podendo ser altamente destrutiva. Incêndios ocorrem na presença simultânea do oxigênio, material combustível e fonte de calor (Marques et al., 2011).

Conforme Brown e Davis (1973), o risco de incêndio (fire risk) está relacionado a probabilidade de um fogo iniciar pela presença e/ou atividade de agentes causadores, enquanto que o perigo de incêndio (fire hazard) está relacionado ao material combustível definido pelo tipo, arranjo, quantidade, condição e localização que forma uma condição especial de ameaça de ignição ou representa dificuldade na extinção do fogo.

$\mathrm{O}$ risco de incêndios ainda pode ser avaliado por meio de fatores fixos e variáveis do ambiente de fogo (por exemplo: combustíveis, condições meteorológicas e topografia) que determinam a facilidade de ignição, a taxa de propagação, a dificuldade de controle e o impacto dos incêndios florestais (Vadrevu et al., 2010).

Flanningan e Harrington (1988), analisaram a relação entre variáveis meteorológicas e a área queimada por incêndios em províncias canadenses. Os resultados mostraram que períodos longos com dias com menos de $1,5 \mathrm{~mm}$ de chuva ou com umidade relativa inferior a $60 \%$ tem maior correlação com a área queimada. Assim, de acordo com esse estudo, os meses com maior ocorrência de incêndios não dependem tanto da quantidade de chuva, porém, principalmente, da frequência de chuvas, temperatura e umidade relativa.

Nos Estados Unidos Estudos, estudos sobre ocorrências de incêndios florestais e suas relações com a distância da rodovia mais próxima, mostraram que a alta densidade de estradas existente ao longo da maior parte dos EUA criam uma situação em que quase todos os incêndios florestais se originam nas cercanias de estradas. Ao mesmo tempo, o acesso fornecido pelas estradas geralmente parece ter um efeito insignificante na capacidade dos bombeiros de controlar grandes incêndios. Conforme observa o autor, os sistemas rodoviários atuais aumentam o risco de incêndio causado pelo homem (Morrison, 2007).

No Brasil, Lazzarini et al. (2012) realizaram estudo sobre os focos de calor no Tocantins, um dos estados brasileiros com maior quantidade de registros. Foram analisados dados entre os anos de 2002 e 2011 em diferentes tipologias de cobertura, uso e ocupação do solo. Especificamente, os autores mostraram que as áreas no entorno das rodovias concentraram $9,8 \%$ do total de registros de focos no período analisado.

Neste artigo, analisou-se, a partir de dados meteorológicos e de focos de calor, a distribuição dos focos de incêndios florestais no entorno de rodovias federais no estado do Ceará/Brasil, com o objetivo de identificar as condições meteorológicas mais propícias e as regiões de maior risco de incêndios. $\mathrm{O}$ estudo neste tema específico apresenta resultados que poderão servir de subsídio para o planejamento de prevenção e mitigação de desastres envolvendo a dinâmica dos transportes e dos incêndios florestais no estado do Ceará.

\section{Materiais e Métodos}

A área de estudo está localizada no estado do Ceará, unidade federativa integrante da região Nordeste do Brasil, com extensão territorial de 148.894,757 quilômetros quadrados, sendo composto por 184 municípios e com população total de 8.452 .381 habitantes, conforme o censo de 2017. O Ceará está localizado, em sua totalidade na sub-região do sertão nordestino, uma área caracterizada pelo clima semiárido. A Caatinga é o bioma característico e representa $88 \%$ da cobertura vegetal do estado. No restante do território encontram-se áreas de vegetação de cerrado, floresta ombrófila, estacional e pioneiras. Em geral a temperatura do ar é alta e pouco variável, espacial e temporalmente, com médias anuais entre $25^{\circ} \mathrm{C}$ e $30^{\circ} \mathrm{C}$ e a disponibilidade hídrica é limitada e altamente variável no tempo e no espaço (Cortez et al., 2017).

A análise da distribuição dos focos de calor foi feita em áreas contíguas às rodovias federais, BR-222, BR-020 e BR-116, a uma distância de até 800 (oitocentos) metros de suas respectivas faixas de domínios.

A escolha da área de estudo justifica-se em decorrência das três rodovias serem as principais vias de acesso ao complexo industrial e portuário do distrito de Pecém, no município de São Gonçalo do Amarante, Ceará.

\subsection{As rodovias em estudo}

A BR-222 é uma rodovia federal que possui 1.811,6 quilômetros de extensão, dos quais, 347 quilômetros estão no estado do Ceará. A rodovia tem início na cidade de Marabá/PA e término na cidade de Fortaleza/CE. A partir do entroncamento com a BR-020 e o Arco Viário, a BR222 e a BR-020 passam a possuir o mesmo trajeto em direção à cidade de Fortaleza. A maior parte da rodovia no estado possui pista simples e acostamento. Ao longo da via tanto as sinalizações horizontais quanto as verticais são encontradas, no geral, estão em estado regular de conservação, sendo, em alguns trechos, a vertical em pior estado que a horizontal (Labtrans, 2015).

A BR-020 é uma rodovia federal radial, com início na cidade de Brasília/DF e término na cidade de Fortaleza/ CE. Em seu projeto total, a via possui 2.038,5 quilômetros 
de extensão, sendo 449 quilômetros no estado do Ceará. Em grande parte do seu trajeto no Ceará, a via possui pista simples e acostamentos em estado regular de conservação. As sinalizações são encontradas, também, em estado regular. Em alguns trechos ao longo da via é visualizado o crescimento da vegetação sobre as sinalizações horizontais e acostamentos (Labtrans, 2015).

A BR-116 é a principal rodovia longitudinal do Brasil. Tem seu início na cidade de Fortaleza/CE e término na cidade de Jaguarão/RS, na fronteira com o Uruguai. Sua extensão total é de aproximadamente 4.542 quilômetros. $\mathrm{Na}$ rodovia existe um grande volume de tráfego de veículos de carga, pelo fato de fazer ligação do nordeste ao sul do País. No Ceará a rodovia possui 544,5 quilômetros e está sob administração pública. Na maior parte dos trechos, a via possui pista simples com acostamentos. Nesses locais o pavimento encontra-se em estado regular.

\subsection{Identificação de focos de calor por meio de sensoriamento remoto}

As potenciais ocorrências de incêndios foram analisadas com base nos registros de focos de calor gerados a partir de imagens do satélite de referência adotado pelo Instituto Nacional de Pesquisas Espaciais (INPE). Esses dados permitem a regularidade de detecção e pelo fato de utilizar um único satélite pode-se verificar a variabilidade espacial e temporal nas ocorrências desses focos. O estudo compreende o período entre 2002 a 2018. Nesse período o satélite de órbita polar AQUA_M-T que opera com sensor MODIS, é o satélite de referência e tem passagem no início da tarde no Brasil.

Para realizar o estudo estatístico sobre as ocorrências de incêndios em vegetações próximas às rodovias no Estado do Ceará, foi realizado o levantamento do total de focos identificados no período de estudo, dentro de todo o território estadual. Em seguida foram selecionados os focos de calor localizados numa faixa de até 800 metros, seguindo o estudo de Morrison (2007), de todas as vias estaduais e federais.

\subsection{Dados meteorológicos}

Os dados de temperatura e umidade relativa do ar foram utilizadas para avaliar as condições do tempo a fim de identificar padrões atmosféricos comuns naquelas situações, bem como períodos mais propícios a ocorrências de incêndios em vegetação. As informações de temperatura e umidade relativa do ar são oriundas das estações convencionais do Instituto Nacional de Meteorologia (INMET), que possuem coleta nos horários sinóticos (00, 12 e 18UTC). Assim, da série de dados disponível, optou-se pelo uso dos dados das 15 horas local (18UTC), que é representativo do período do dia em que a umidade relativa do ar é mais baixa e favorece a ocorrência dos incêndios florestais (Oliveira et al., 2015).
Também foram utilizados dados de precipitação total anual provenientes da rede pluviométrica convencional operada pela Fundação Cearense de Meteorologia e Recursos Hídricos (FUNCEME), para verificar se há correlação entre precipitação total e número de focos de calor.

\section{4. Índice de risco de Incêndio florestal de Angstron}

Desenvolvido na Suécia, segundo Soares (1985), este índice baseia-se fundamentalmente na temperatura e na umidade relativa do ar. É um índice não-acumulativo e a sua equação é a seguinte:

$$
I_{A}=0,05 H-\left(\frac{T-27}{10}\right)
$$

onde $I_{A}$ é o índice de Angstron; $H$ é a umidade relativa (\%) e $T$ é a temperatura $\left({ }^{\circ} \mathrm{C}\right)$.

Para a análise de padrões atmosféricos propícios a ocorrência de incêndios florestais, seguiu-se Oliveira et al. (2015) que observou que sempre que $I_{A}$ for menor que 2,5 as condições são de Altíssimo Risco de incêndio florestal. Por outro lado, valores acima deste, não representariam risco, sob o ponto de vista meteorológico, para estas ocorrências.

\subsection{Análise de distribuição espacial dos focos de calor}

Para análise da distribuição espacial dos focos de calor identificados, necessárias para melhorar as estratégias de prevenção (Yang et al., 2007), foram elaborados mapas utilizando o software livre QGIS, baseado no Sistema de Informação de Geográfica (SIG).

\section{Resultados e Discussão}

Entre 2002 e 2018, um total de 45.773 focos foram registrados no Ceará, o que dá em média, 2.692 focos por ano. $\mathrm{O}$ ano com maior número de registros foi o ano de 2003, com um total de 4.856 focos e o ano com menor registro de focos foi 2015, com registro de 841 focos. A Fig. 1 apresenta um gráfico com o total anual de focos de calor registrados entre os anos de 2002 e 2018, em todo o território do Estado do Ceará.

Conforme mostra a Tabela 1, os focos de calor tendem a se concentrar no segundo semestre.

Em relação às precipitações totais anuais, conforme observam Cortez et al. (2017), apresentam alta variabilidade espacial e temporal ao longo do ano, concentrandose entre os meses de fevereiro a maio, período denominado de quadra chuvosa, quando se observa cerca de $70 \%$ do volume anual de chuva, Tabela 2. Esses dados confirmam que o período propício para ocorrência de focos de calor no estado é o segundo semestre, entre os meses de setembro e dezembro, após o período de chuvas.

No período em estudo observou-se que alguns anos com chuva reduzida, por exemplo, 2014 e 2015, tiveram também menor registro de focos de calor comparado a 


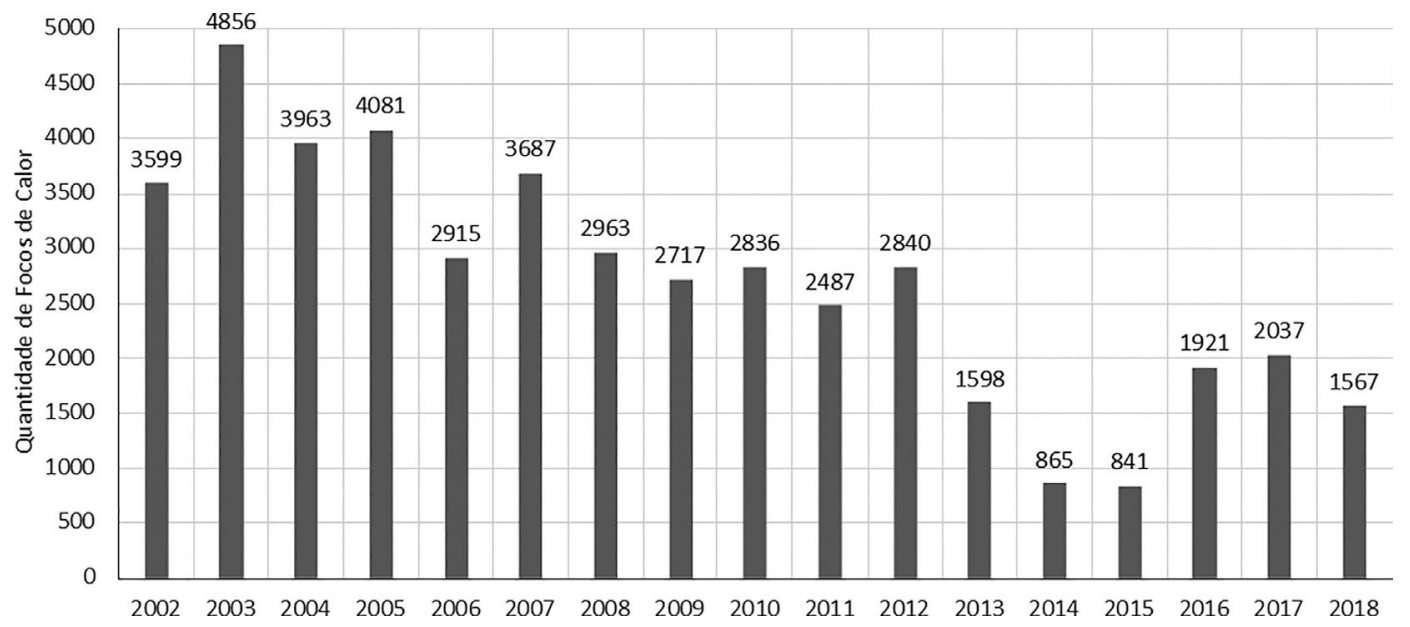

Figura 1 - Total anual de focos de calor a partir do satélite de referência no Ceará para os anos de 2002 a 2018 (Fonte: BDQueimadas/INPE).

Tabela 1 - Focos de calor mensais e total anual a partir do satélite de referência no Ceará para os anos de 2002 a 2018 (Fonte: BDQueimadas/INPE).

\begin{tabular}{cccccccccccccc}
\hline Ano & Jan & Fev & Mar & Abr & Mai & Jun & Jul & Ago & Set & Out & Nov & Dez & Total \\
\hline 2002 & 0 & 0 & 0 & 0 & 0 & 0 & 10 & 65 & 131 & 954 & 1433 & 1006 & $\mathbf{3 5 9 9}$ \\
2003 & 222 & 8 & 7 & 3 & 0 & 3 & 13 & 93 & 305 & 1047 & 1763 & 1392 & $\mathbf{4 8 5 6}$ \\
2004 & 137 & 6 & 1 & 2 & 2 & 3 & 17 & 53 & 167 & 706 & 1461 & 1408 & $\mathbf{3 9 6 3}$ \\
2005 & 357 & 37 & 11 & 4 & 1 & 6 & 12 & 45 & 194 & 906 & 1385 & 1123 & $\mathbf{4 0 8 1}$ \\
2006 & 178 & 42 & 3 & 1 & 0 & 0 & 5 & 56 & 196 & 526 & 889 & 1019 & $\mathbf{2 9 1 5}$ \\
2007 & 331 & 5 & 3 & 0 & 1 & 1 & 13 & 153 & 258 & 808 & 1215 & 899 & $\mathbf{3 6 8 7}$ \\
2008 & 155 & 17 & 6 & 0 & 0 & 2 & 4 & 33 & 147 & 574 & 978 & 1051 & $\mathbf{2 9 6 3}$ \\
2009 & 308 & 8 & 3 & 0 & 0 & 0 & 7 & 20 & 81 & 346 & 838 & 1106 & $\mathbf{2 7 1 7}$ \\
2010 & 199 & 58 & 42 & 6 & 3 & 3 & 47 & 142 & 249 & 432 & 1284 & 371 & $\mathbf{2 8 3 6}$ \\
2011 & 23 & 3 & 10 & 1 & 0 & 4 & 19 & 35 & 189 & 314 & 882 & 1007 & $\mathbf{2 4 8 7}$ \\
2012 & 237 & 40 & 9 & 3 & 18 & 32 & 40 & 189 & 413 & 684 & 673 & 502 & $\mathbf{2 8 4 0}$ \\
2013 & 111 & 59 & 35 & 6 & 5 & 5 & 4 & 34 & 97 & 245 & 517 & 480 & $\mathbf{1 5 9 8}$ \\
2014 & 89 & 15 & 7 & 3 & 5 & 14 & 36 & 93 & 106 & 205 & 148 & 144 & $\mathbf{8 6 5}$ \\
2015 & 39 & 6 & 3 & 1 & 3 & 2 & 5 & 40 & 65 & 185 & 256 & 236 & $\mathbf{8 4 1}$ \\
2016 & 3 & 1 & 2 & 5 & 4 & 0 & 73 & 173 & 239 & 602 & 456 & 363 & $\mathbf{1 9 2 1}$ \\
2017 & 65 & 8 & 5 & 10 & 10 & 27 & 26 & 99 & 288 & 463 & 513 & 523 & $\mathbf{2 0 3 7}$ \\
2018 & 114 & 7 & 5 & 3 & 4 & 11 & 28 & 107 & 208 & 284 & 438 & 358 & $\mathbf{1 5 6 7}$ \\
\hline
\end{tabular}

anos com maior volume de precipitação. Sabe-se que parte dos incêndios florestais decorrem de queimadas para a limpeza e preparo da terra para plantio, por exemplo, e isso tem maior incidência em anos de chuvas mais abundantes. Por outro lado, nesses mesmos anos, após a estação de chuvas, a quantidade de material para queima (vegetação seca) também é mais abundante, assim, a incidência de incêndios florestais ou focos de calor registrados por satélite podem ser maiores nos anos em que houve registro de precipitação total anual acima da média histórica. De fato, quando se calcula a correlação de Pearson, o valor é de apenas 0,32 , que indica uma relação positiva entre precipitação anual e número de focos de calor, embora não seja uma relação linear forte.
Os totais mensais e anuais dos focos de calor localizados dentro da faixa de 800 metros das rodovias federais e estaduais no Estado Ceará são apresentados a seguir na Tabela 3.

De acordo com esses dados, entre 2002 e 2018 foram registrados um total de 3.408 focos de calor no entorno das rodovias federais e estaduais que cortam o estado. Isso representa $7 \%$ do total de focos que foi de 45.773 registros. Ao longo dos anos, esse percentual variou entre 5\% a $12 \%$ (Tabela 4).

$\mathrm{O}$ ano com maior percentual de focos no entorno das rodovias foi 2014 , com $12 \%$ dos eventos, o que corresponde a 103 focos, do total de 865 registrados naquele ano. Observa-se que 2014, está entre os dois anos com 
Tabela 2 - Precipitação mensal e total anual no Ceará para os anos de 2002 a 2018 (Fonte: FUNCEME).

\begin{tabular}{lccccccccccccc}
\hline Ano & Jan & Fev & Mar & Abr & Mai & Jun & Jul & Ago & Set & Out & Nov & Dez & Total \\
\hline 2002 & 245,1 & 49,4 & 187,1 & 176,1 & 92,7 & 37,3 & 16,1 & 0,3 & 0,6 & 0,4 & 2,7 & 10,4 & $\mathbf{8 1 8 , 2}$ \\
2003 & 99,9 & 179,4 & 267,2 & 156,2 & 67,1 & 47,4 & 1,5 & 1,4 & 0,1 & 0,9 & 1,9 & 12,7 & $\mathbf{8 3 5 , 7}$ \\
2004 & 406,1 & 246,1 & 139,9 & 82,2 & 55,6 & 76,5 & 21,3 & 2,0 & 0,9 & 0,5 & 1,3 & 6,4 & $\mathbf{1 0 3 8 , 8}$ \\
2005 & 61,1 & 51,1 & 194,8 & 94,5 & 104,5 & 41,8 & 5,4 & 1,3 & 0,1 & 0,0 & 1,0 & 28,4 & $\mathbf{5 8 4 , 0}$ \\
2006 & 24,1 & 124,0 & 188,7 & 206,8 & 136,5 & 45,8 & 5,9 & 3,2 & 0,9 & 4,5 & 2,8 & 22,2 & $\mathbf{7 6 5 , 4}$ \\
2007 & 24,0 & 246,5 & 120,2 & 154,6 & 48,9 & 29,7 & 4,6 & 0,3 & 0,2 & 0,3 & 1,6 & 38,9 & $\mathbf{6 6 9 , 8}$ \\
2008 & 99,1 & 95,5 & 332,5 & 239,1 & 104,8 & 17,8 & 10,8 & 9,5 & 0,3 & 0,5 & 0,4 & 12,8 & $\mathbf{9 2 3 , 1}$ \\
2009 & 111,9 & 143,9 & 207,9 & 380,5 & 244,8 & 64,4 & 40,3 & 16,6 & 0,7 & 1,9 & 1,9 & 11,1 & $\mathbf{1 2 2 5 , 9}$ \\
2010 & 88,9 & 24,5 & 73,7 & 159,5 & 44,6 & 26,2 & 2,9 & 0,0 & 0,0 & 32,5 & 1,6 & 88,2 & $\mathbf{5 4 2 , 6}$ \\
2011 & 212,9 & 169,6 & 156,4 & 196,9 & 136,1 & 31,2 & 50,2 & 11,5 & 0,5 & 50,5 & 12,8 & 5,8 & $\mathbf{1 0 3 4 , 4}$ \\
2012 & 54,0 & 138,1 & 93,2 & 52,6 & 18,6 & 19,5 & 6,6 & 0,3 & 0,1 & 0,3 & 1,7 & 4,0 & $\mathbf{3 8 9 , 0}$ \\
2013 & 37,6 & 61,6 & 78,4 & 132,1 & 92,2 & 60,6 & 29,7 & 1,4 & 0,4 & 2,7 & 17,9 & 36,7 & $\mathbf{5 5 1 , 3}$ \\
2014 & 46,6 & 91,9 & 158,3 & 124,9 & 85,1 & 10,2 & 5,2 & 0,3 & 2,4 & 10,1 & 24,7 & 5,8 & $\mathbf{5 6 5 , 5}$ \\
2015 & 27,8 & 96,3 & 178,4 & 106,4 & 37,7 & 36,6 & 36,5 & 0,8 & 0,3 & 0,3 & 0,1 & 11,6 & $\mathbf{5 3 2 , 8}$ \\
2016 & 191,8 & 53,2 & 129,4 & 97,4 & 47,4 & 17,6 & 1,0 & 0,1 & 0,7 & 0,2 & 0,6 & 27,5 & $\mathbf{5 6 6 , 9}$ \\
2017 & 68,3 & 159,9 & 206,2 & 116,1 & 69,4 & 26,8 & 30,8 & 1,7 & 0,6 & 1,4 & 2,8 & 14,1 & $\mathbf{6 9 8 , 1}$ \\
2018 & 68,1 & 197,0 & 127,8 & 216,5 & 59,2 & 10,6 & 13,8 & 1,2 & 0,1 & 3,4 & 15,8 & 88,7 & $\mathbf{8 0 2 , 2}$ \\
\hline
\end{tabular}

Tabela 3 - Total mensal e anual de focos de calor identificados dentro da faixa de 800 metros de rodovias que cortam o estado do Ceará para os anos de 2002 a 2018 (Fonte: BDQueimadas/INPE).

\begin{tabular}{cccccccccccccc}
\hline Ano & Jan & Fev & Mar & Abr & Mai & Jun & Jul & Ago & Set & Out & Nov & Dez & Total \\
\hline 2002 & 0 & 0 & 0 & 0 & 0 & 0 & 2 & 16 & 19 & 78 & 79 & 65 & 259 \\
2003 & 5 & 0 & 0 & 6 & 3 & 4 & 1 & 20 & 51 & 57 & 36 & 40 & 223 \\
2004 & 7 & 2 & 0 & 0 & 0 & 0 & 1 & 3 & 24 & 48 & 82 & 69 & 236 \\
2005 & 19 & 5 & 2 & 0 & 0 & 1 & 2 & 8 & 17 & 72 & 86 & 58 & 270 \\
2006 & 15 & 5 & 1 & 0 & 0 & 0 & 1 & 9 & 41 & 48 & 60 & 53 & 233 \\
2007 & 27 & 0 & 0 & 0 & 0 & 0 & 3 & 33 & 40 & 55 & 71 & 41 & 270 \\
2008 & 6 & 1 & 1 & 0 & 0 & 0 & 0 & 8 & 33 & 43 & 63 & 63 & 218 \\
2009 & 20 & 1 & 0 & 0 & 0 & 0 & 2 & 3 & 15 & 35 & 71 & 72 & 219 \\
2010 & 9 & 2 & 3 & 0 & 1 & 0 & 8 & 23 & 32 & 27 & 78 & 21 & 204 \\
2011 & 2 & 1 & 3 & 0 & 0 & 0 & 1 & 9 & 42 & 30 & 49 & 64 & 201 \\
2012 & 21 & 0 & 0 & 0 & 1 & 6 & 5 & 26 & 31 & 47 & 49 & 37 & 223 \\
2013 & 7 & 6 & 4 & 1 & 1 & 0 & 0 & 8 & 9 & 15 & 27 & 30 & 108 \\
2014 & 7 & 0 & 2 & 0 & 0 & 2 & 11 & 20 & 20 & 22 & 12 & 8 \\
2015 & 0 & 1 & 0 & 0 & 1 & 0 & 0 & 8 & 9 & 7 & 17 & 16 \\
2016 & 0 & 0 & 0 & 1 & 0 & 0 & 15 & 34 & 35 & 58 & 41 & 15 \\
2017 & 5 & 0 & 0 & 6 & 3 & 4 & 1 & 20 & 51 & 57 & 36 & 40 \\
2018 & 10 & 0 & 2 & 0 & 1 & 2 & 7 & 22 & 36 & 19 & 34 & 26 \\
\hline
\end{tabular}

menor registro de focos do período em análise. Por outro lado, o ano com o maior número de registros de focos de calor, teve apenas $5 \%$ dos focos no entorno das rodovias, ou seja, 242, de um total anual de 4.856 .

Embora a análise considere apenas focos de calor e não incêndios florestais efetivamente, observa-se que os percentuais são muito menores aos obtidos em estudos como o de Morrison (2007), que verificou que 90,1\% dos incêndios florestais nos Estados Unidos ocorrem dentro de uma faixa de 800 metros de distância de uma estrada. O autor observa que a grande densidade de rodovias existente naquele país contribui para esse expressivo percen- 
Tabela 4 - - Percentual de focos de calor no entorno de rodovias em relação ao total anual registrado no Ceará para os anos de 2002 a 2018 (Fonte: BDQueimadas/INPE).

\begin{tabular}{|c|c|}
\hline Ano & $\begin{array}{l}\text { Percentual de focos de calor no entorno de rodovias em relação ao } \\
\text { total anual }\end{array}$ \\
\hline 2002 & $7 \%$ \\
\hline 2003 & $5 \%$ \\
\hline 2004 & $6 \%$ \\
\hline 2005 & $7 \%$ \\
\hline 2006 & $8 \%$ \\
\hline 2007 & $7 \%$ \\
\hline 2008 & $7 \%$ \\
\hline 2009 & $8 \%$ \\
\hline 2010 & $7 \%$ \\
\hline 2011 & $8 \%$ \\
\hline 2012 & $8 \%$ \\
\hline 2013 & $7 \%$ \\
\hline 2014 & $12 \%$ \\
\hline 2015 & $7 \%$ \\
\hline 2016 & $10 \%$ \\
\hline 2017 & $11 \%$ \\
\hline 2018 & $10 \%$ \\
\hline
\end{tabular}

tual de incêndios entorno dessas rodovias. Nesse sentido, em comparação aos Estados Unidos, a malha rodoviária no Ceará é menor e assim, seria de se esperar, sob esse argumento, que o registro de focos de calor no entorno dessas vias seja, comparativamente, reduzido. $\mathrm{O}$ resultado obtido no Ceará, por outro lado, aproxima-se ao de Lazzarini et al. (2012) que estudando os focos no estado do Tocantins, encontrou, nas áreas no entorno das rodovias daquele estado, $9,8 \%$ do total de registros de focos.

Os focos de calor nas proximidades das três rodovias em estudo, BR 116, 020 e 222, representam cerca de $27 \%$ (926 focos) do total de focos registrados em todo o Estado. Desse total, a BR 222, responde por $46 \%$ dos focos, seguida da BR 116 (30\%) e BR 020 (24\%).

$\mathrm{O}$ mapeamento dos focos de calor em torno das três rodovias em estudo (BR 222, BR 116 e BR 020) permitiu visualizar e identificar os trechos onde estes são registrados de forma mais frequente. A Fig. 2 apresenta o mapa referente ao ano de 2003, como exemplo, destacando a localização dos focos de incêndio nas três rodovias em estudo.

A partir do mapeamento, foi analisada a localização dos focos de calor em cada um dos municípios cortados por cada uma das três rodovias.

Conforme mostra a Tabela 5, na BR 020, dez municípios tiveram registro de focos de calor, sendo que nos trechos que passam pelos municípios de Caucaia, Canindé, Caridade, Boa Viagem e Tauá foram identifica$\operatorname{dos} 18,53 \%, 15,12 \%, 13,17 \%, 11,70 \%$ e $11,70 \%$, respectivamente, do total de focos de calor no entorno dessa

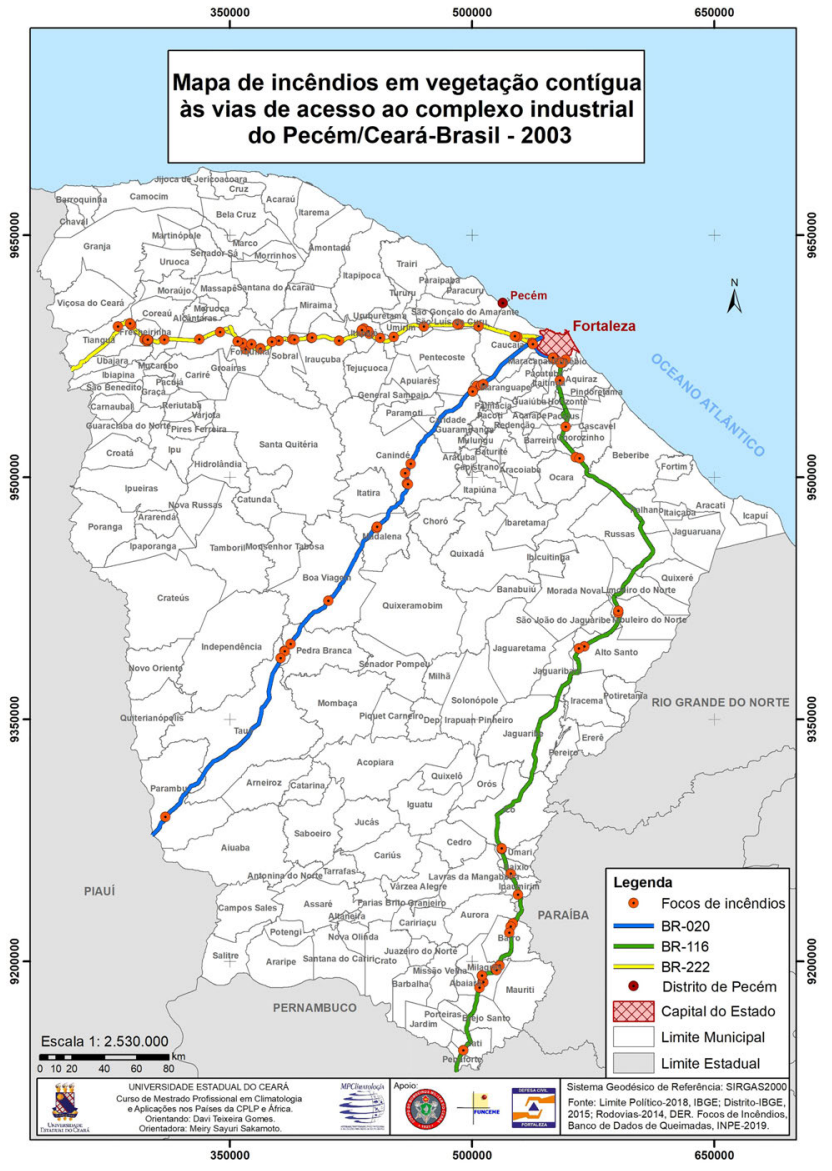

Figura 2 - Mapa com focos de calor no entorno das rodovias BR 020, BR 116 e BR 222 em 2003. Fonte: BDMEP/INPE.

Tabela 5 - - Total e percentual de focos de calor, por município, identificados no entorno da rodovia BR 020, no Ceará, entre os anos de 2002 a 2018 (Fonte: BDQueimadas/INPE).

\begin{tabular}{lcc}
\hline Município & Total de Focos & Percentual \\
\hline Caucaia & 38 & $18,53 \%$ \\
Canindé & 31 & $15,12 \%$ \\
Caridade & 27 & $13,17 \%$ \\
Boa Viagem & 24 & $11,70 \%$ \\
Tauá & 24 & $11,70 \%$ \\
Maranguape & 21 & $10,24 \%$ \\
Parambu & 14 & $6,83 \%$ \\
Madalena & 11 & $5,36 \%$ \\
Itatira & 10 & $4,87 \%$ \\
Pedra Branca & 5 & $2,44 \%$ \\
\hline
\end{tabular}

rodovia entre 2002 e 2018. Assim, na BR 020, as áreas de maior risco a incêndio estão localizadas nos municípios de Caucaia, Canindé, Caridade, Boa Viagem e Tauá.

$\mathrm{Na} \mathrm{BR} 116,27$ municípios cortados por esta rodovia tiveram registro de focos de calor identificados entre os anos de 2002 e 2018, Tabela 6. Os trechos que apresentam maior frequência de registro de focos e, consequente- 
Tabela 6 - Total e percentual de focos de calor, por município, identificados no entorno da rodovia BR 116, no Ceará, entre os anos de 2002 a 2018. (Fonte: BDQueimadas/INPE).

\begin{tabular}{|c|c|c|}
\hline Município & Total de Focos & Percentual \\
\hline Russas & 33 & $11,8 \%$ \\
\hline Icó & 31 & $11,1 \%$ \\
\hline Milagres & 29 & $10,4 \%$ \\
\hline Ipaumirim & 25 & $9,0 \%$ \\
\hline Barro & 24 & $8,6 \%$ \\
\hline Chorozinho & 15 & $5,4 \%$ \\
\hline Brejo Santo & 14 & $5,0 \%$ \\
\hline Jati & 13 & $4,7 \%$ \\
\hline Itaitinga & 9 & $3,2 \%$ \\
\hline Aquiraz & 8 & $2,9 \%$ \\
\hline Pacajus & 8 & $2,9 \%$ \\
\hline Horizonte & 7 & $2,5 \%$ \\
\hline Penaforte & 7 & $2,5 \%$ \\
\hline Alto Santo & 5 & $1,8 \%$ \\
\hline Cascavel & 5 & $1,8 \%$ \\
\hline Jaguaribe & 5 & $1,8 \%$ \\
\hline Ocara & 5 & $1,8 \%$ \\
\hline Palhano & 5 & $1,8 \%$ \\
\hline Umari & 5 & $1,8 \%$ \\
\hline Eusébio & 4 & $1,4 \%$ \\
\hline Fortaleza & 4 & $1,4 \%$ \\
\hline Limoeiro do Norte & 4 & $1,4 \%$ \\
\hline Baixio & 3 & $1,1 \%$ \\
\hline Beberibe & 3 & $1,1 \%$ \\
\hline Porteiras & 3 & $1,1 \%$ \\
\hline Tabuleiro do Norte & 3 & $1,1 \%$ \\
\hline Morada Nova & 2 & $0,7 \%$ \\
\hline
\end{tabular}

mente, representam maior risco para incêndios florestais são os trechos que percorrem Russas, Icó, Ipaumirim e Barro.

$\mathrm{Na}$ BR 222, treze municípios cortados pela rodovia tiveram registro de focos de calor. Os municípios com maior frequência de registros de focos foram Caucaia, São Gonçalo do Amarante, Sobral, Forquilha e Itapajé, com $20,2 \%, 13,2 \%, 13,2 \%, 9,4 \%$ e $7,5 \%$ de focos, respectivamente, Tabela 7.

As Figs. 3 e 4 mostram, respectivamente, as médias mensais de temperatura e umidade relativa do ar, às 15 horas locais, em cinco municípios cearenses, que representam as diferentes regiões do estado: o litoral (For-

Tabela 7 - - Total e percentual de focos de calor, por município, identificados no entorno da rodovia BR 222, no Ceará, entre os anos de 2002 a 2018 (Fonte: BDQueimadas/INPE).

\begin{tabular}{lcc}
\hline Município & Total de Focos & Percentual \\
\hline Caucaia & 86 & $20,8 \%$ \\
São Gonçalo do Amarante & 56 & $13,5 \%$ \\
Sobral & 56 & $13,5 \%$ \\
Forquilha & 40 & $9,6 \%$ \\
Itapajé & 32 & $7,7 \%$ \\
Frecheirinha & 28 & $6,7 \%$ \\
Umirim & 26 & $6,2 \%$ \\
Tianguá & 24 & $5,8 \%$ \\
Irauçuba & 20 & $4,8 \%$ \\
Fortaleza & 19 & $4,6 \%$ \\
Coreaú & 13 & $3,1 \%$ \\
São Luís do Curu & 8 & $1,9 \%$ \\
Tejuçuoca & 1 & $0,2 \%$ \\
\hline
\end{tabular}

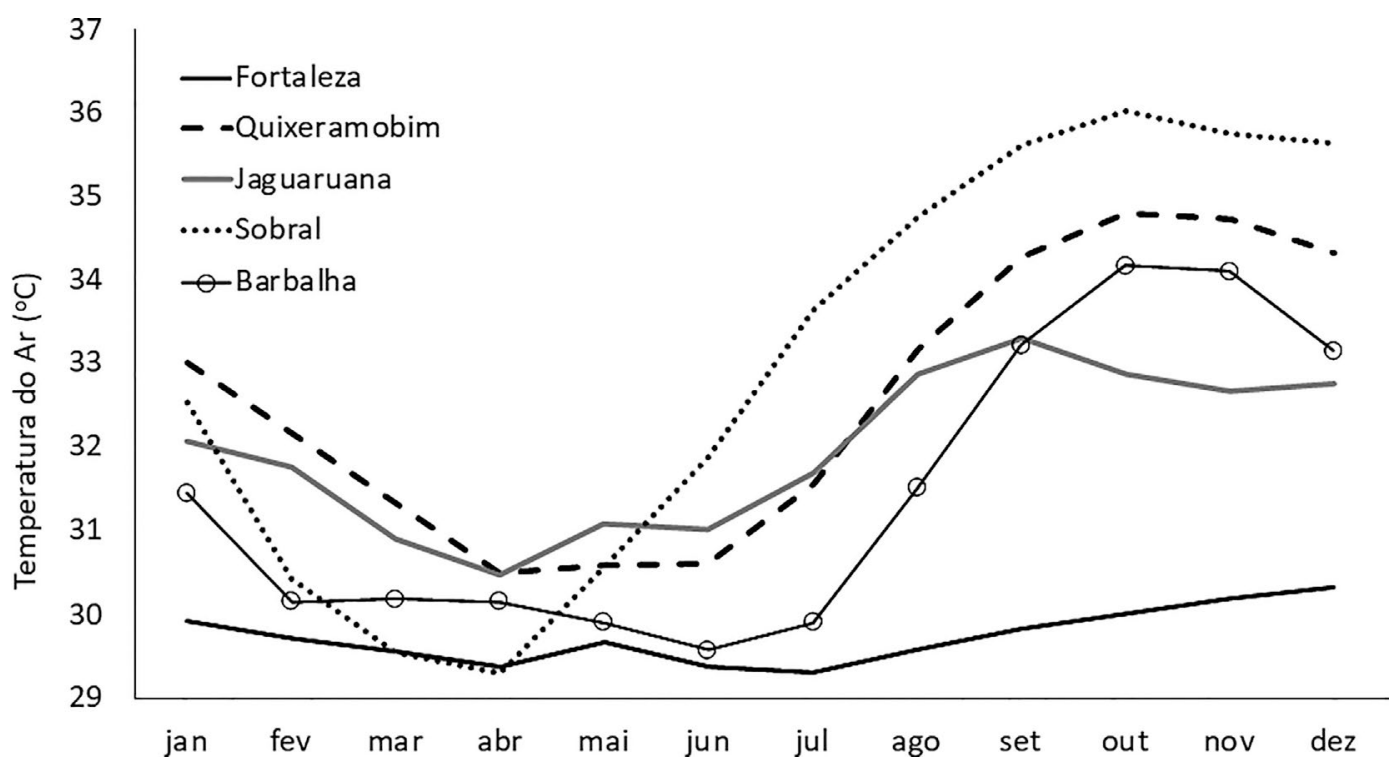

Figura 3 - Temperatura do ar média mensal $\left({ }^{\circ} \mathrm{C}\right)$ das 15 horas local nos municípios cearenses de Fortaleza, Quixeramobim, Jaguaruana, Sobral e Barbalha (período de 2002 a 2018) (Fonte: INMET). 


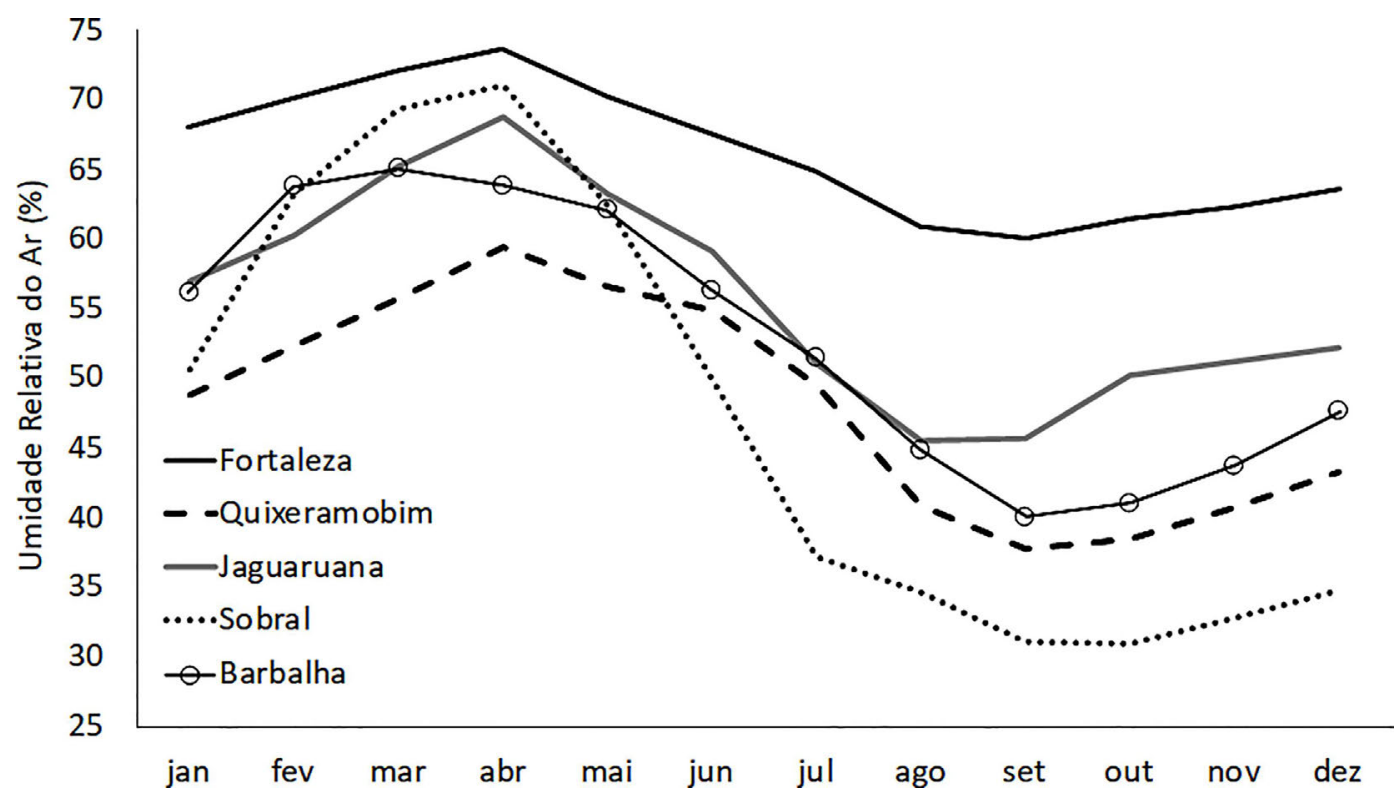

Figura 4 - Umidade relativa do ar média mensal (\%) das 15 horas local nos municípios cearenses de Fortaleza, Quixeramobim, Jaguaruana, Sobral e Barbalha (período de 2002 a 2018) (Fonte: INMET).

taleza), a região norte (Sobral), a região do Sertão (Quixeramobim), a região leste (Jaguaruana) e a região sul (Barbalha). Os dados mostram que em todas as regiões, principalmente, aquelas mais distantes do litoral, a variabilidade anual desses campos é bastante evidente. No segundo semestre, as temperaturas são mais altas e a umidade relativa mais baixa, favorecendo a ocorrência de incêndios florestais nessa época do ano. Esse resultado concorda com a maior incidência de focos de calor detectada entre setembro e dezembro.
O índice de Angstron médio mensal calculado para esses municípios é mostrado na Fig. 5. Como se pode observar, excetuando-se Fortaleza, os demais municípios apresentam, no segundo semestre, valores do índice menores do que 2,5, denotando, segundo Oliveira et al. (2015), Altíssimo Risco para ocorrência de incêndio florestal. Em Fortaleza, embora o índice de Angstron não aponte alto risco para ocorrência de incêndios, observa-se que no segundo semestre, os valores são mais baixos do que aqueles registrados no primeiro semestre, ficando entre 2,5 e 3 .

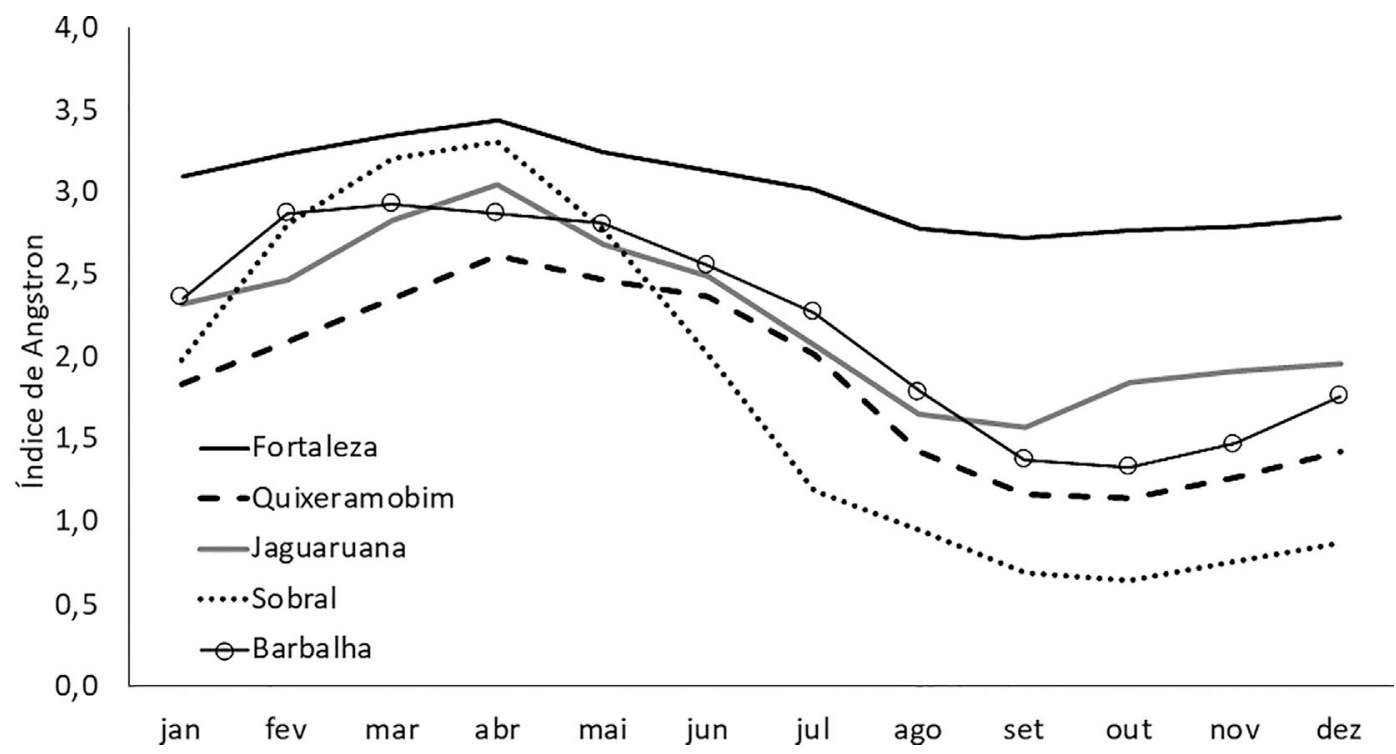

Figura 5 - Índice de Angstron médio mensal das 15 horas local nos municípios cearenses de Fortaleza, Quixeramobim, Jaguaruana, Sobral e Barbalha (período de 2002 a 2018) (Fonte de dados: INMET; cálculo do autor). 


\section{Conclusões}

Os resultados mostram que, no Ceará, cerca de $87 \%$ dos focos de calor são observados entre os meses de setembro a dezembro, quando a precipitação é reduzida no estado. Observou-se que a relação entre precipitação anual e total de focos de calor não é direta, ou seja, anos mais secos, não apresentam, necessariamente, maior quantidade de focos de calor. Esse resultado reforça outros estudos, como o de Soriano et al. (2015) que também encontraram baixa correlação entre precipitação e focos de calor.

O percentual de focos de calor no entorno de rodovias cearenses é em média cerca de 7\% do total de focos registrados no estado. Ao longo dos anos estudados esse percentual variou entre $5 \%$ a $12 \%$, próximos aos valores obtidos por Lazzarini et al. (2012), em seu estudo sobre os focos de calor no estado do Tocantins. Foi possível, a partir dos dados dos focos de calor registrados por satélite, identificar os municípios com maior risco a incêndios florestais nas três rodovias estudadas. A análise dos resultados do Índice de risco de Incêndio de Angstron sugere que o segundo semestre é o período que apresenta condições atmosféricas favoráveis a ignição e propagação rápida de incêndios em vegetação, principalmente no interior do Ceará. Os resultados sugerem que o litoral, por influência da maritimidade e do regime de chuvas mais prolongado, não apresenta alto índice de risco de incêndio, contudo as regiões do interior alcançaram valores do IA abaixo de 2,5, característico de Altíssimo Risco de incêndio florestal.

\section{Referências}

BROWN, A.A.; Davis, K.P. Forest Fire: Control and Use. New York: McGraw-Hill, 1973.

CORTEZ, H.S.; LIMA, G.P.; SAKAMOTO, M.S. A Seca 20102016 e as Medidas do Estado do Ceará Para Mitigar Seus Efeitos. Parcerias Estratégicas, v. 22, n. 44, p. 83-118, 2017.

FLANNIGAN, M.; HARRINGTON, J.B. A Study of the Relation of Meteorological Variables to Monthly Provincial
Area Burned by Wildfire in Canada (1953-80). Journal of Applied Meteorology, v. 27, n. 4, p. 441-452, 1988.

LABTRANS, Laboratório de Transportes e Logística. Plano Mestre: Terminal. Portuário do Pecém. Cooperação Técnica para Apoio à Sep/Pr no Planejamento do Setor Portuário Brasileiro e na Implantação dos Projetos de Inteligência Logística Portuária. Florianópolis: Labtrans, 2015.

LAZZARINI, G.M.J.; FERREIRA, L.C.C.; FELICÍSSIMO, M.F.G.; LIRA, R.G.; JUSTINO, A.G.; GOMES, C.; RIBEIRO, J.C.N.; MAGALHÃES, G.R.D. Análise da Distribuição de Focos de Calor no Tocantins Entre 2002 e 2011. Revista Interface, v. 5, n. 5, p. 24-35, 2012.

MARQUES, S.; BORGES J.G.; GARCIA-GONZALO, J.; MOREIRA, F.; CARREIRAS J.M.B. et al. Characterization of Wildfires in Portugal. European Journal Forest Research, v. 130, n. 5, p. 775-784, 2011.

MORRISON, P.H. Roads and Wildfires. Washington: Pacific Biodiversity Institute, Winthrop, 40 p., 2007.

OLIVEIRA, M.C.F.; JUNIOR, J.A.S.; CRUZ, P.P.N.; FILHO, J.D.S. Risco de Ocorrência de Queimada e de Incêndio e as Medidas de Prevenções, em Belém - PA, Ano de 2015 (Fire and Burning Occurrence Risk, and Contingency Measures, in Belém/Pará/Brazil, Year of 2015). Revista Brasileira de Geografia Física, v. 9, n. 4, p. 1030-1042, 2016.

SOARES, R.V. Inceêndios Florestais: Controle e Uso do Fogo. Curitiba: Fundação de Pesquisas Florestais do Parana, 213 p., 1985.

SORIANO, B.M.A.; DANIEL, O.; SANTOS, S.A. Eficiência de Índices de Risco de Incêndios Para o Pantanal Sul-Matogrossense. Ciência Florestal, v. 25, n. 4, p. 809-816, 2015.

VADREVU, K.P.; EATURU, A.; BADARINATH, K.V.S. Fire Risk Evaluation Using Multicriteria Analysis: A Case Study. Environmental Monitoring Assessment, v. 166, n. 1-4, p. 223-229, 2010.

YANG, J.; HEALY, H.S.; SHIFLEY, S.R.; GUSTAFSO, E.J. Spatial Patterns of Modern Period Human-Caused Fire Occurrence in the Missouri Ozark Highlands. Forest Science, v. 53, n.1, p. 1-15, 2007.

License information: This is an open-access article distributed under the terms of the Creative Commons Attribution License (type CC-BY), which permits unrestricted use, distribution and reproduction in any medium, provided the original article is properly cited. 